\title{
THE ENZYMATIC SYNTHESIS OF SIALYL-LACTOSE*
}

\author{
G. W. Jourdian, D. M. Carlson, ${ }^{* *}$ and S. Roseman \\ Rackham Arthrit1s Research Unit and Dept. of Biological Chemistry, \\ The University of Michigan, Ann Arbor, Michigan
}

Received January 25, 1963

Sialyl-1actose (SL) was first isolated from lactating rat mamary gland by Trucco and caputto (1954). In subsequent extensive studies on milk oligosaccharides, Kuhn and coworkers (Kuhn and Brossmer, 1958; Kuhn, 1958) obtained two isomers of SL from human milk, one being identical to SL from bovine colostrum. Bovine SL was shown to be N-acetylneuraminy1-(2 $\rightarrow 3)-\beta-D-g a l a c t o-$ pyranosy1-(1 - 4)-D-glucose, 1.e., SL- $(2+3)$. The other SL from human milk is $\mathrm{N}$-acetylneuraminy $1-(2 \rightarrow 6)-B-D-g a 1$ actopyranosyl-( $\rightarrow 4)-D-g$ lucose, i.e., $\mathrm{SL}-(2 \rightarrow 6)$.

We now wish to report the enzymatic synthesis of sialyl-lactose by a particulate preparation from rat inamary gland. Chromatographic and periodate oxidation data indicate that the product is SL- $(2 \rightarrow 3)$. In addition, preliminary evidence shows that this preparation catalyzes the synthesis of other trisaccharides, such as sialyl-galactosyl-acetylglucosamine.

Materials and Methods. The following compounds were prepared as pre-

* The Rackham Arthritis Research Unit is supported by a grant from the Horace H. Rackham School of Graduate Studies of The University of Michigan. This investigation was supported by grants from the National Institute of Health, and from the American Cancer Society.

** Post-doctoral Fellow, National Institutes of Health.

** We should like to express our gratitude to Dr. Richard Kuhn for the 3 analogues of $\beta$-D-galactopyranosyl-acetylglucosamine, the two isomers of SL$(2 \rightarrow 3$, and $2 \rightarrow 6)$, and for a paper chromatographic method for separating these compounds; also to Drs. Bernard L. Horecker and Harlyn Halvorson for varlous galactosides; to Dr. Nelson Richtmyer for neolactose; to Mr. William Suomi for D-galactose oxidase (Avigad, et al., 1962); and to Dr. J. F. Reithel for crystalline $\beta$-galactosidase.

The following solvent systems were used for paper chromatographic experiments: (A) n-butanol, n-propanol, $0.1 \mathrm{~N} \mathrm{HCl}(1: 2: 1)$; (B) ethanol, ammonia, water $(80: 1: 20)$; (C) n-butanol, acetic acid, water $(5: 1: 4)$; (D) ethyl acetate, pyridine, water $(2: 1: 2)$; (E) n-butanol, pyridine, water $(6: 4: 3)$; (F) ethyl acetate, pyridine, water $(2: 1: 1) ;(G)$ methyl ethyl ketone, acetone, water, formic acid (3:1:1:0.1); (H) ethyl acetate, pyridine, acetic acid, water $(5: 5: 1: 3)$. 
viously described: $\mathrm{N}$-acetyl- and $\mathrm{N}-\mathrm{glycolylneuraminic}$ acid-1-C $\mathrm{C}^{14}\left(\mathrm{~N} / \mathrm{N}-1-\mathrm{C}^{14}\right.$ and NGN-1- $\mathrm{C}^{14}$ ) (Brunetti, et al., 1962); cytidine-5'-monophospho-stalic acid-

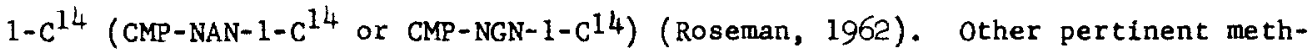
ods are given in the earlier papers. Bovine SL- $(2 \rightarrow 3)$ was prepared according to the method of Schneir, et al. (1962).

A general method has been developed for the determination of sialy1transferases, i.e., enzymes that catalyze the transfer of sialic acids from CMP-sialic acids to acceptors. The method utilizes CMP-sialic acid-1-C ${ }^{14}$ (NAN or NGN) as substrate, and assumes that the product of the enzyme-catalyzed reaction (sialyl-glycosides such as sialyl-lactose) is more stable to acid hydrolysis than is CMP-sialic acid. The following steps are involved: Mild acid hydrolysis of the incubation mixture to convert residual CMPsialic acid to free sialic acid. (2) Reduction of the free sialic acid to dihydro-sialic acid or "sialltol" with $\mathrm{NaBH}_{4}$, a reagent that does not attack sialyl-glycosides. (3) Hydrolysis and decarboxylation of the sialyl-1-c ${ }^{14}$. glycosides with strong acid and heat under conditions that do not significantly decompose sialitol. The $\mathrm{C}^{14} \mathrm{O}_{2}$ liberated in the last step is therefore a measure of sialyl-glycoside formed in the enzymatic reaction.

Enzyme Preparation. Mammary glands from actively lactating, albino rats (Rawley Farms, Plymouth, Mich.) were homogenized in a Potter-Elvehjem homogenizer at $0-4^{\circ}$ using $2 \mathrm{ml}$ of the following solution per gram of tissue: $0.1 \mathrm{M}$ potassium phosphate buffer, $\mathrm{pH} 6.9,0.01 \mathrm{M} \mathrm{Mg}$ acetate, $0.006 \mathrm{M}$ mercaptoethano1. After straining the suspension through gauze, it was centrifuged for $15 \mathrm{~min}$ at $1000 \mathrm{rpm}(121 \times \mathrm{g})$, the lipid layer removed, and the supernatant fluid centrifuged at $39,000 \times \mathrm{g}$ for $1 \mathrm{hr}$. The precipitate was washed from one to three times with buffer, and resuspended in the same buffer; the final protein concentration was $25 \mathrm{mg}$ per ml.

Enzymatic Synthesis and Characterization of Sialyl-1actose. Lactose is an acceptor of sialyl groups (Table I). For purposes of characterization, the

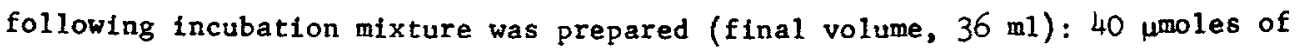
CMP-NAN-1-C ${ }^{14}$ (1.30 × $10^{6} \mathrm{cpm}$ per $\mu$ mole), $300 \mu$ moles of 1actose, 2.3 mmoles of 
TABLE I

Specificity of the Sialyl-transferase System*

\begin{tabular}{|c|c|c|c|}
\hline \multicolumn{2}{|l|}{ Acceptor } & \multicolumn{2}{|c|}{$\mathrm{c}^{14}$ incorporated into product from } \\
\hline Trivial name & Structure $e^{* *}$ & CMP-NAN-1-C 14 & CMP-NGN-1-C 14 \\
\hline & & cpm & $\mathrm{cpm}$ \\
\hline Lactose & $\beta-G a l-(1 \rightarrow 4)-G l u$ & 6400 & 5200 \\
\hline Neolactose & $B-G a l-(1 \rightarrow 4)-A 1 t$ & 2600 & 1400 \\
\hline N-Acetyllactosamine & $B-G a 1-(1-4)-A C G m$ & 5800 & 5400 \\
\hline Lacto-N-biose I & $B-G a 1-(1 \rightarrow 3)-A c G m$ & 4400 & 5800 \\
\hline & $B-G a 1-(1 \rightarrow 6)-A c G m$ & 4300 & 3900 \\
\hline \multicolumn{2}{|c|}{ o-Nitropheny $1-\beta-D-g a l$ ac topyranoside } & 3200 & 5300 \\
\hline \multicolumn{2}{|c|}{ o-Ni tropheny $1-\alpha-D-g a l$ ac topyranos 1 de } & 680 & 390 \\
\hline Galactose & & 600 & \\
\hline Melibiose & $\alpha-G a l-(1 \rightarrow 6)-G l u$ & 450 & \\
\hline Cellobiose & B-Glu- $(1 \rightarrow 4)-G l u$ & 520 & \\
\hline Colominic acid & $(\mathrm{NAN})_{\mathfrak{n}}$ & 10 & \\
\hline
\end{tabular}

* The incubation mixtures contained the following components in $0.10 \mathrm{ml}$ : $10 \mu$ moles potassium phosphate buffer, pH 6.9; $0.5 \mu$ mole of "acceptor"; 0.011

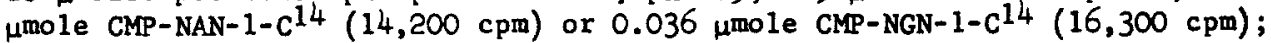
and $0.05 \mathrm{ml}$ of the enzyme preparation described in the text. Incubations were conducted for $8 \mathrm{hr}$ at $37^{\circ}$ and assayed as described in the text. The quantities presented above are averages of duplicate determinations and have been corrected for the endogenous values. The average deviation between duplicate incubation mixtures was approximately 10\%; the extreme deviations were $1 \%$ and $20 \%$. Endogenous values, obtained by omitting acceptor sugars from the incubation mixtures, averaged 1800 with CMP-NAN-1-C ${ }^{14}$, and 1770 with CMP-NGN-1-C14. Boiled enzyme control values were 970 and 820 respectively. NAN and NGN, in the presence or absence of CTP, ATP, etc., were not significantly incorporated. The high endogenous value, and the variability between duplicate samples led us to define a compound as an inactive acceptor if the level of $\mathrm{c}^{14}$ incorporated was less than $700 \mathrm{cpm}$ over the endogenous value, i.e., less than $11 \%$ of the result obtained with lactose.

* The abbreviations are: Gal, D-galactopyranose; Glu, D-glucose or Dglucopyranose; AcGm, N-acetyl-D-glucosamine; Alt, D-altrose.

potassium phosphate buffer, $\mathrm{pH} 6.9,225 \mathrm{mg}$ of protein (i.e., $9 \mathrm{ml}$ of the enzyme preparation described above). The mixture was slowly agitated during 
Incubation for $15 \mathrm{hr}$ at $37^{\circ}$. Three volumes of absolute ethanol were then added, the mixture was maintained for 30 min at $37^{\circ}$, and the resulting precipitate washed 3 times with $75 \%$ ethanol. The supernatant fluids were combined, concentrated to a small volume, applied to a column containing Dowex-1, bicarbonate resin and fractionated with a linear gradient of $\mathrm{NH}_{4} \mathrm{HCO}_{3}(0.0$ to $0.4 \mathrm{M})$. The product (20 $\mu$ moles), comprising the major radioactive peak, was eluted in the range 0.025 to $0.070 \mathrm{M}$ bicarbonate. The pooled fractions were concentrated in vacuo to decompose $\mathrm{NH}_{4} \mathrm{HCO}_{3}$, and the residual material was characterized as SL$\mathrm{C}^{14}$ in the manner described below.

The product migrated with bovine SL on paper electrophoresis in $0.05 \mathrm{M}$ citrate buffer, $\mathrm{pH} 4.5$, or in $0.05 \mathrm{M}$ sodium tetraborate. Nelther CMP-NAN nor NAN were detected in the preparation (concentrations greater than $1 \%$ would have been observed). The $\mathrm{c}^{14}$ product co-chromatographed with bovine SL in solvent systems $F$ and $G$ as demonstrated by autoradiographic techniques. Comparison of the product with authentic SL- $(2 \rightarrow 3)$, and $S L-(2 \rightarrow 6)$ in solvent system $H$ showed the presence of only the $2 \rightarrow 3$ isomer.

Treatment of the isolated product with purified clostridial neuraminidase (Cassidy, et al., 1962), resulted in the quantitative 1iberation of NAN-C 14 (paper chromatography in solvent systems A and B) and lactose (paper chromatography in solvent systems $C, D, B)$. The lactose was treated with B-galactosidase, yielding glucose and galactose (paper chromatography in solvent systems $C, D$ and $E$ ). These hexoses were also identifled after acid hydrolysis of the intact trisaccharide. The monosaccharides were enzymatically characterized as shown in Table II. The Table presents the analyses of the intact trisaccharide and its hydrolysis products.

These results show that the particulate preparation catalyzed the synthesis of SL. Paper chromatography suggests that the product is the $2 \rightarrow 3$ isomer, and this conclusion is supported by studies indicating that the galactose moiety of the trisaccharide is resistant to oxidation by periodate. More precise analytical data must be obtained, however, before it is concluded that all of the galactose is resistant. 
TABLE II

Analyses of Enzymatically Synthesized SI

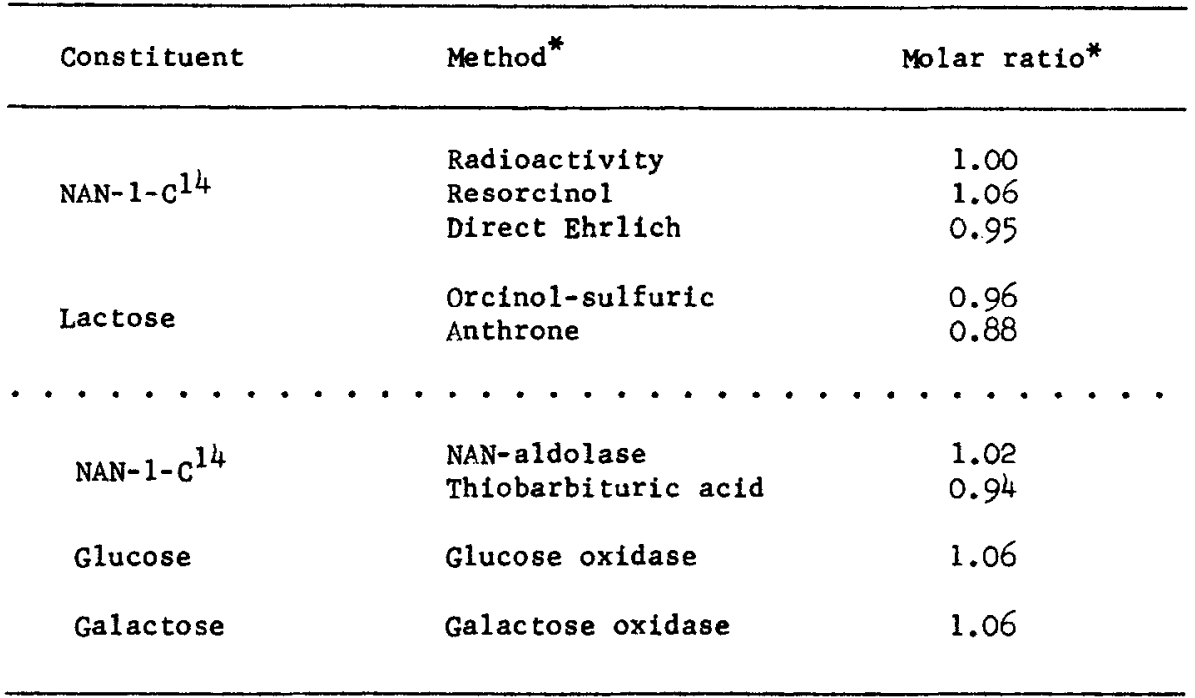

The values above the dotted line were obtained by analysis of the intact trisaccharide, while those below the 1 ine were obtained by: (a) treatment of the trisaccharide with neuraminidase prior to assay with NAN-aldolase or thiobarbituric acid; (b) hydrolysis for $3 \mathrm{hr}$ at $100^{\circ}$ with $1 \mathrm{~N} \mathrm{H}_{2} \mathrm{SO}_{4}$ (followed by deionization) prior to analysis with the hexose oxidases. The specific activity of NAN-1- $\mathrm{C}^{14}$ was the same as that of the substrate, CMP-NAN- $1-\mathrm{C}^{14}\left(1.30 \times 10^{6} \mathrm{cpm} / \mu\right.$ mole $)$. All values are related to the concentration of NAN as determined by its $c^{14}$ content.

Specificity Studies. As shown in Table I, both CMP-NAN and CMP-NGN serve as sialyl donors with the particulate enzyme preparation. To determine the structural requirements for acceptor activity, 49 carbohydrates and carbohydrate derivatives were examined. Twelve compounds were active; some of these are listed in Table $I$, along with some defined as Inactive.

The structural feature common to all acceptors is the presence of a $B-D-$ galactopyranosyl end group. Among the inactive compounds were simple sugars (e.g., acetylgalactosamine), glycosides, di- and oligosaccharides, colominic acid (a polymer of NAN (Barry, 1958)), and several glycoprotelns that had been treated with neuraminidase. Sugar nucleotides such as UDP-galactose were inactive, except the nucleotide disaccharide, B-D-galactopyranosyl-acetylglucosaminyl-UDP. The product obtained with the latter was identified as sialyl- 
galactosyl-acetylglucosaminyl-1-P. We have not yet established whether cleavage of the pyrophosphate bond in the UDP-oligosaccharide occurs before or after transfer of the sialyl residue. If the hydrolysis step occurs after the transfer reaction, then the first product(s) formed would be similar or identical to the UDP-trisaccharides previously isolated from colostrum (Jourdian, et al., 1961).

An important class of compounds, not yet tested, are $\mathrm{N}$-acetylgalactosaminides, since glycoproteins and glycolipids are thought to contain sialic acid linked to galactose and/or acetylgalactosamine.

The endogenous value, given in the Footnote to Table $I$, was observed in all experiments. The $\mathrm{C}^{14}$ was rapidly incorporated, reaching a maximum at about $10 \mathrm{~min}$, and remained constant thereafter. These results were in sharp contrast to those obtained when lactose was present in the incubation mixture, the maximum being reached in 3 to $8 \mathrm{hr}$. The nature of the apparent endogenous acceptor is now under investigation.

Discussion.* The results presented above show that sialy1-1actose $(2 \rightarrow 3)$ was enzymatically formed when a washed particulate preparation from rat mammary gland was incubated with CMP-NAN and lactose. CMP-NGN also served as a sialic acid donor. A variety of sugars, all containing B-D-galactopyranosyl end groups, acted as acceptors. Whether the sialy1-transferase system consists of a non-specific enzyme, or a mixture of specific enzymes, remains to be determined.

The sialy1-transferase system may function in the biogenesis of lowmolecular weight oligosaccharides (perhaps at the nucleotide level). It may also be involved in the synthesis of higher-molecular welght oligosaccharides and of polysaccharides found in milk and colostrum (Kuhn, 1958; György, 1958), and in the biosynthesis of glycoproteins and glycolipids.

The rat mammary gland sialyl-transferase differs sharply in its acceptor requirements from the only other known transferase of this type, 1.e., a part-

* The isolation and chemistry of SL has been reviewed (Z111iken and Whitehouse, 1958). 
iculate preparation from E. col1 $\mathrm{R}-235$ that catalyzes the synthesis of the homopolysaccharide, colominic acid (Aminoff, et al., 1963).

\section{REFERENCES}

Aminoff, D., Dodyk, F., and Roseman, S., J. Biol. Chem. (in press) (1963). Avigad, G., Amaral, D., Asensio, C., and Horecker, B. L., J. Biol. Chem., 237, 2736 (1962).

Barry, G. T., J. Expt1. Med., 107, 507 (1958).

Brunetti, P., Jourdian, G. W., and Roseman, S., J. Biol. Chem., 237, 2447 (1962).

Cassidy, J. T., Jourdian, G. W., and Roseman, S., Bacteriological Proc. (62nd Annual Meeting), p. 63 (1962).

György, $P_{.}$, in Wolstenholme, G. E. W. and $O^{\prime}$ Connor, M., Ciba Found. Symp. "Chemistry and Btology of Mucopolysaccharides," p. 140, Little, Brown and Company, Boston (1958).

Jourdian, G. W., Shimizu, F., and Roseman, S., Federation Proc., 20, 161 (1961).

Kuhn, R., in Wolfrom, M. L. (Ed1tor) "Carbohydrate Chemistry of Substances of Biological Interest." (Fourth Int'1 Congress Biochm., Vienna (1958))

Vol. I, Symp. I, p. 67. Pergamon Press Inc., New York (1959).

Kuhn, R. and Brossmer, R., Angew. Chem., 70, 25 (1958).

Schneir, M., Winzler, R. J., and Rafelson, M. E., Jr., in Coon, M. J.

(Editor) "Btochemical Preparations", Vol. 9, p. 1. John Wiley and Sons, Inc., New York (1962).

Trucco, R. E., and Caputto, R., J. Biol. Chem., 206, 901 (1954).

Zilliken, F., and Whitehouse, M. W., in Wolfrom, M. L., and Tipson, R. S., (Editors) "Advances in Carbohydrate Chemistry", Vol. 13, p. 237, Academic Press Inc., New York (1958). 